\title{
Editorial-the 5th International workshop on modeling the ocean (IWMO 2013)
}

\author{
Jarle Berntsen • Lie-Yauw Oey • Tal Ezer • \\ Richard Greatbatch · Huijie Xue · Yasumasa Miyazawa
}

Received: 13 August 2014 / Accepted: 13 August 2014 / Published online: 31 August 2014

(C) Springer-Verlag Berlin Heidelberg 2014

The 5th International Workshop on Modeling the Ocean (IWMO http://www.uib.no/en/IWMO2013/-58927/iwmo2013-bergen-norway) was held in June 17-20, in Bergen, Norway. The historic city of Bergen is the gateway to the fjords and a center for oceanic research. The workshop was hosted by the University of Bergen and also sponsored by the Research Council of Norway. Approximately 80 researchers worldwide participated in the workshop. Professor Mellor, Princeton University, gave the keynote lecture. The 5th IWMO meeting in Bergen was the first IWMO held in Europe, followed on the footsteps of previous meetings, IWMO-2009 in Taipei, Taiwan

Responsible Editor: Jörg-Olaf Wolff

J. Berntsen $(\bowtie)$

Department of Mathematics, University of Bergen,

Bergen, Norway

L.-Y. Oey

Institute of Hydrological and Oceanic Sciences, National Central

University, Jhongli, Taiwan

L.-Y. Oey

Atmospheric and Oceanic Science Program, Princeton University, Princeton, NJ 08544, USA

T. Ezer

Department of Ocean, Earth and Atmospheric Sciences,

Old Dominion University, Norfolk, VA, USA

R. Greatbatch

GEOMAR Helmholtz Centre for Ocean Research, Kiel, Germany

H. Xue

School of Marine Science, University of Maine, Orono, ME, USA

Y. Miyazawa

Japan Agency for Marine-Earth Science and Technology

(JAMSTEC), Yokohama City, Kanagawa, Japan
(Oey et al. 2010a, b), IWMO-2010 in Norfolk, USA (Ezer et al. 2011), IWMO-2011 in Qingdao, China (Oey et al. 2013a), and IWMO-2012 in Yokohama, Japan (Oey et al. 2013b). The participants presented approximately 60 oral talks and 20 posters, covering a wide range of ocean modeling and data analysis topics, as described below. In the spirit of promoting young scientists in their early career (graduate students and postdocs), about 15 young presenters participated in the Outstanding Young Scientist Award (OYSA) competition and three of them received awards.

The 16 papers selected for the special issue underwent the rigorous review and revisions process as regular papers in Ocean Dynamics, with at least two reviewers for each paper; reviewers were selected from both the workshop attendees and other respected researchers from the ocean modeling community at large.

The papers in this Topical Collection covers many aspects of numerical ocean modeling. There are seven papers on analysis of model outputs, data-assimilation or numerical methods (Backeberg et al. 2014; Chang and Oey 2014; Dominicis et al. 2014; Hjelmervik and Hjelmervik 2014; Miyama and Miyazawa 2014; Xu and Oey 2014; Wang et al. 2014a). Three of the papers address air-sea interactions and upper layer physics (Broström et al. 2014; Esau 2014; Troitskaya et al. 2014). There are three papers on regional processes (Lien et al. 2014; Nelko et al. 2014; Saramul and Ezer 2014) and one on coastal processes (Wang et al. 2014b). Physical-biological processes in a coastal system are addressed in Guo et al. (2014) and overflows between ocean basins is the topic in Cuthbertson et al. (2014).

Backeberg et al. (2014) configured a regional HYCOM (Hybrid Coordinate Ocean Model) to test the Ensemble Optimal Interpolation (EnOI) data assimilation scheme to simulate the Agulhas Current system and associated 
mesoscale eddies. The inner nested model has a resolution of $10 \mathrm{~km}$ with 30 hybrid layers, and along-track sealevel anomaly data is used for assimilation. The authors assessed the skill of the assimilation model by comparing the results against velocity and eddy kinetic energy (EKE) derived from independent (i.e., not used for assimilation) drifter data. They also compared the results against AVISO data (http://www.aviso.oceanobs.com) and results from a free-running experiment without assimilation. Although the assimilation model does not beat persistence (from AVISO), the level of EKE is in better agreement with the drifter data. It will be interesting in the future to compare their results with those obtained using the Princeton Ocean Model (POM) and different assimilation schemes (e.g., Miyazawa et al. 2012; Xu et al. 2013; Xu and Oey 2014).

Chang and Oey (2014) used a parallelized version of the POM to analyze eddies that are generated by the instability of the North Pacific Subtropical Counter Current (STCC). Once eddies are identified in the simulations, they are analyzed using the Okubo-Weiss method. The results show that the temperature and salinity distributions are most favorable for eddies to grow in March and April while September and October offer the most unfavorable conditions. The authors show that the seasonal difference is dominated by the seasonal evolution of the front in the top $100 \mathrm{~m}$ of the water column which is strongest in winter and spring.

Dominicis et al. (2014) used the Interactive Relocatable Nested Ocean Model (IRENOM), based on the Harvard Ocean Prediction System (HOPS), to simulate possible oil spill tracks during the Costa Concordia cruise ship grounding incident. IRENOM, together with an oil spill model, simulates ocean currents, possible oil spill scenarios, and drifter trajectories. Drifters released in the area of the accident were compared with model simulations. The simulated trajectories were found to be sensitive to the spatial resolution of the meteorological fields used, providing higher prediction skills with higher resolution wind forcing.

Hjelmervik and Hjelmervik (2014) described a new method to analyze time-averaged oceanographic fields based on the combination of historic and real-time measurements. Unlike standard averaging that may result in smoothing, the method employs empirical orthogonal functions and clustering into representative climatological regions, using a training data set. The improved estimate is based on optimization approach that minimizes the difference between the real-time measurements and the final estimate. The method can be useful for climate studies, ocean model validation and operational forecast systems.

Miyama and Miyazawa (2014) analyzed the JCOPE2 (Japan Coastal Ocean Predictability Experiment 2) results at $1 / 36^{\circ}$-resolution to study frontal instability waves along the Kuroshio. The JCOPE2 is based on a parallel version of the POM. These waves have periods of 8-36 days and wavelengths of about $300 \mathrm{~km}$, and are shown to exist in the model downstream of a coastal cape off the southern coast of Japan. Detailed analyzes of the flow energetics suggest that the waves are produced by barotropic and baroclinic instability of the Kuroshio as the jet accelerates past the cape. The velocity shear is more intense, and the temperature gradients are stronger when the Kuroshio is nearshore and disturbances then become more energetic.

Wang et al. (2014a) tested an alternative leapfrog scheme (ALF) for the barotropic equations, which may replace the standard leapfrog scheme (SLF) now used in the POM. The ALF scheme has no computational mode, it can work without the Asselin filter, and it can use a longer time step than the SLF does. The scheme is tested for the seamount case with the same set up as in Ezer et al. (2002). Though the splitting errors are relatively small in both schemes, the tests show that the errors are further reduced by replacing the SLF with the ALF. Moreover, the flow near the seamount seems to be quite sensitive to the choice of the time stepping method.

$\mathrm{Xu}$ and Oey (2014) used the local ensemble transformation Kalman Filter (LETKF) combined with the parallelized POM to the state estimation of the South China Sea (SCS) circulation. LETKF reasonably outperforms the optimum interpolation data assimilation scheme in representation of the observed features in the western North Pacific Ocean state including transports through various straits in SCS. In the Luzon Strait, the state estimation confirms, for the first time, the three layer transport structure previously deduced in the literature from sparse observations: westward in the upper and lower layers and eastward in the middle layer. The authors demonstrate that the representation of the three layer structure is robust to the model configurations; an unassimilated simulation of a North Pacific Ocean model is used for the detailed analysis of the three layer structure. Potential vorticity and mass conservations suggest a basin-wide cyclonic circulation in the upper layer of SCS $(z>-570 \mathrm{~m})$, an anti-cyclonic circulation in the middle layer $(-570 \mathrm{~m} \geq z>-2,000 \mathrm{~m})$, and in the abyssal basin $(\leq-2,000 \mathrm{~m})$ the circulation is cyclonic in the north and anti-cyclonic in the south.

Broström et al. (2014) examined whether the CoriolisStokes force influences the budget of the kinetic energy of the mean flow and concluded that the answer is no. The result is consistent with the traditional view that since Coriolis force is a virtual force it does not impact the energy budget. This is an important issue in the wave-current community. It is interesting that the results are actually already implicitly given by Mellor $(2003,2008)$, who showed that the Coriolis-Stokes force does not appear if the mean kinetic energy is defined using the Lagrangian mean velocity; see also Aiki and Greatbatch (2012). 
Esau (2014) used the Parallelized Atmospheric largeeddy simulation model (PALM) to model the atmospheric boundary and oceanic surface boundary layers in coupled mode. In the initial condition, the atmospheric surface temperature is colder than the sea surface temperature allowing for the development of convection in both boundary layers. The study shows that the ocean mixed layer (OML) convective cells try to organize the atmospheric boundary layer (ABL) cells so that water downdrafts in the OML tend to be co-located with air updrafts in the ABL. The study shows that the convective structures in the ABL and the OML are co-organised with the OML convection controlling the air-sea exchange in the quasi-equilibrium ABL-OML system.

Troitskaya et al. (2014) applied a quasi-linear model of wind-wave coupling to describe the turbulent boundary layer over steep surface waves. The simplified model is verified with a set of Particle Image Velocimetry (PIV) measurements and Direct Numerical Simulation (DNS), all of which demonstrate that the flow velocity field averaged over an ensemble of turbulent fluctuations is smooth without flow separation from the crest of the waves.

Lien et al. (2014) used the Regional Ocean Modeling System (ROMS) to examine the temperature and salinity anomalies in the eastern Nordic Sea. The model successfully reproduces the major Great Salinity Anomalies (GSAs) since 1960. In addition, the model simulation reveals the intra-seasonal variability in the depth of the upper-slope Atlantic Water induced by the along-slope wind, which appears to be modulated by the North Atlantic Oscillation. These Regional Wind-generated Anomalies (RWAs) occur more or less simultaneously along the Norwegian continental slope.

Nelko et al. (2014) investigated the roles of the tidal forcing in the sea level variability in the SCS using the advanced numerical ocean model with the unstructured grids: SUNTANS (Fringer et al. 2006). Comparison with the simulated and observed surface elevations shows that the model generally well reproduces the variability observed in the SCS coastal regions. Sensitivity experiments demonstrate the effectiveness of the unstructured grids for representation of the topography affecting the model skill. Detailed validation of the simulation results suggests that the wind forcing as well as the tidal forcing contributes to the sea level variability in some parts of SCS.

Saramul and Ezer (2014) used a high-resolution POM to study the dynamics of the Upper Gulf of Thailand, which is a unique, low latitudes wide, and shallow system driven by rivers and monsoonal winds. Seasonal reversal of the wind-driven circulation and the generation of coastal jets were simulated, as well as the impact of the Coriolis effect on river plumes and gyres. Results from the 3D numerical model were compared well with an analytical solution.
El Niño and La El Niña patterns affected cloudiness in the region, thus surface heat fluxes in the model had to include cloud coverage to accurately simulate interannual variations in water temperatures.

Wang et al. (2014b) used a 3-level nested version of the Regional Ocean Modeling System (ROMS) to study the plume from the Copper River in the northern Gulf of Alaska. A passive tracer is used to delineate the growth and decay of the plume and to diagnose the spread of the Copper River discharge on the neighboring shelf. A realistic simulation is described for the years 2010 and 2011. The absence of strong storms in 2010 allows a buoyant bulge to develop outside the Copper River estuary that is eventually broken down by frontal instability processes that interact with the Alaskan Stream to induce transport pulses across the shelf break. On the other hand, in 2011, a downwelling favorable wind event in early August accelerated the southwestward coastal current producing an intense downstream transport event. Both processes lead to a fast drain of the plume and its associated buoyancy content.

Guo et al. (2014) used a 3D physical-biological model to study the seasonal dynamics and biological processes in the central California Current Systems. The model compared well with remote sensing and in situ observations. Coastal species peak in the late upwelling period, May-July, while oceanic species peak in August-October. The model describes the seasonal variations in phytoplankton biomass and zooplankton, their relation to stratification and winddriven upwelling, and the differences between the coastal and the offshore ecosystems.

Cuthbertson et al. (2014) investigated the flow of dense water in the Faroese Channels with the Massachusetts Institute of Technology General Circulation Model, combined with laboratory experiments representing the FaroeShetland Channel, the Wyville-Thomson Basin and Ridge and the Faroe Bank Channel. The range of parametric conditions under which dense water flow over the WyvilleThomson Ridge is investigated. The Burger number, a volume flux parameter, and the deep-water inflow lengthratio specified at the inlet are controlling the overflow across the ridge. Cyclonic and anti-cyclonic eddies and gyres are key features both in observations from the laboratory experiments and in the results from the numerical simulations. These features affect the dense water outflow pathways and they promote spillage over the Wyville-Thomson Ridge.

Acknowledgments We want to thank the Chief Editor of Ocean Dynamics Professor Jörg-Olaf Wolff for all help and assistance throughout the editing process. We thank all reviewers for their help in ensuring that accepted papers have the high standard of Ocean Dynamics. The IWMO-2013 was supported by the University of Bergen and the Research Council of Norway. We thank the local Bergen organizers for help during the meeting. 


\section{References}

Aiki H, Greatbatch RJ (2012) Thickness-weighted mean theory for the effect of surface gravity waves on mean flows in the upper ocean. J Phys Oceanogr 42(5):725-747. doi:10.1175/JPO-D11-095.1

Backeberg B, Counillio F, Johannessen JJ, Pujol M-I (2014) Assimilating along-track SLA data using the EnOI in an eddy resolving model of the Agulhas system. Ocean Dyn 64:1121-1136. doi:10.1007/s 10236-014-0717-6

Broström G, Christensen KH, Drivdal M, Weber JEH (2014) Note on Coriolis-Stokes force and energy. Ocean Dyn 64:1039-1045. doi:10.1007/s10236-014-0723-8

Chang Y-L, Oey L-Y (2014) Analysis of STCC eddies using the Okubo-Weiss parameter on model and satellite data. Ocean Dyn 64:259-271. doi:10.1007/s10236-013-0680-7

Cuthbertson A, Davies P, Stashchuk N, Vlasenko V (2014) Model studies of dense water overflows in the Faroese Channels. Ocean Dyn 64:273-292. doi:10.1007/s10236-013-0685-2

Dominicis MD, Falchetti S, Trotta F, Pinardi N, Giacomelli L, Napolitano E, Fazioli L, Sorgente R, Haley P, Lermusiaux P, Martins F, Cocco M (2014) A relocatable ocean model in support of environmental emergencies. The Costa Concordia emergency case. Ocean Dyn 64:667-688. doi:10.1007/s10236-014-0705-x

Esau I (2014) Indirect air-sea interactions simulated with a coupled turbulence-resolving model. Ocean Dyn 64:689-705. doi:10.1007/s10236-014-0712-y

Ezer T, Arango H, Shchepetkin AF (2002) Developments in terrainfollowing ocean models: Intercomparisons of numerical aspects. Ocean Model 4:249-267. doi:10.1016/S1463-5003(02)00003-3

Ezer T, Oey L-Y, Xue H, Wang XH (2011) Editorial - The 2nd International Workshop on Modeling the Ocean (IWMO-2010). Ocean Dyn 61:1287-1289. doi:10.1007/s10236-011-0470-z

Fringer OB, Gerritsen M, Street RL (2006) An unstructured-grid, finite-volume, nonhydrostatic, parallel coastal-ocean simulator. Ocean Model 14:139-278. doi:10.1016/j.ocemod.2006.03.006

Guo L, Chai F, Xiu P, Xue H, Rao S, Liu Y, Chavez FP (2014) Seasonal dynamics of physical and biological processes in the central California Current System: A modeling study. Ocean Dyn 64:1137-1152. doi:10.1007/s10236-014-0721-x

Hjelmervik K, Hjelmervik KT (2014) Time-calibrated estimates of oceanographic profiles using empirical orthogonal functions and clustering. Ocean Dyn 64:655-665. doi:10.1007/s10236014-0704-y

Lien VS, Gusdal Y, Vikebø FB (2014) Along-shelf hydrographic anomalies in the Nordic Seas (1960-2011): locally generated or advected signals? Ocean Dyn 64:1047-1059. doi:10.1007/s10236-014-0736-3

Mellor G (2003) The three-dimensional current and surface wave equations. J Phys Oceanogr 33:1978-1989. doi:10.1175/15200485(2003)033<1978:TTCASW > 2.0.CO;2
Mellor G (2008) The depth-dependent current and wave interaction equations: a revision. J Phys Oceanogr 38:2587-2596. doi:10.1175/2008JPO3971.1

Miyama T, Miyazawa Y (2014) Short-term fluctuations south of Japan and their relationship with the Kuroshio path: 8- to 36-day fluctuations. Ocean Dyn 64:537-555. doi:10.1007/s10236-0140701-1

Miyazawa Y, Miyama T, Varlamov SM, Guo X, Waseda T (2012) Open and coastal seas interactions south of Japan represented by an ensemble Kalman Filter. Ocean Dyn 62:645-659. doi:10.1007/s10236-011-0516-2

Nelko V, Saha A, Chua VP (2014) On the tidally driven circulation in the South China Sea: Modeling and analysis. Ocean Dyn 64:413428. doi:10.1007/s10236-013-0687-0

Oey L-Y, Ezer T, Miyazawa Y, Wu C-R (2010a) EditorialInternational Workshop on Modeling the Ocean (IWMO) special issue in ocean dynamics. Ocean Dyn 60:299-300. doi:10.1007/s10236-010-0281-7

Oey L-Y, Ezer T, Miyazawa Y, Wu C-R (2010b) EditorialInternational Workshop on Modeling the Ocean (IWMO) special issue part 2 in ocean dynamics. Ocean Dyn 60:1271-1272. doi:10.1007/10.1007/s10236-010-0338-7

Oey L-Y, Ezer T, Qiu B, Berntsen J, He R (2013a) Editorial-The 3rd International Workshop on Modeling the Ocean (IWMO 2011). Ocean Dyn 63:307-309. doi:10.1007/s10236-013-0595-3

Oey L-Y, Miyazawa Y, Aiki H, Masumoto Y, Ezer T, Waseda T (2013b) Editorial - the 4th International Workshop on Modeling the Ocean (IWMO 2012). Ocean Dyn 63:1345-1347. doi:10.1007/s10236-013-0658-5

Saramul S, Ezer T (2014) On the dynamics of low latitude, wide and shallow coastal system: Numerical simulations of the Upper Gulf of Thailand. Ocean Dyn 64:557-571. doi:10.1007/s10236-014-0703-z

Troitskaya Y, Sergeev DA, Druzhinin O, Kandaurov AA, Ermakova OS, Ezhova EV, Esau I, Zilitinkevich S (2014) Atmospheric boundary layer over steep surface waves. Ocean Dyn 64:11531161. doi:10.1007/s10236-014-0743-4

Wang Q, Zhou W, Wang D (2014a) Implementation of new time integration methods in POM. Ocean Dyn 64:643-654. doi:10.1007/s10236-014-0707-8

Wang Y, Xue H, Chai F, Chao Y, Farrara J (2014b) A model study of the Copper River plume and its effects on the northern Gulf of Alaska. Ocean Dyn 64:241-258. doi:10.1007/s10236-013-0684-3

Xu F-H, Oey L-Y (2014) State analysis using the Local Ensemble Transform Kalman Filter (LETKF) and the three-layer circulation structure of the Luzon Strait and the South China Sea. Ocean Dyn 64:905-923. doi:10.1007/s10236-014-0720-y

Xu F-H, Oey L-Y, Miyazawa Y, Hamilton P (2013) Hindcasts and forecasts of Loop Current and eddies in the Gulf of Mexico using local ensemble transform Kalman filter and optimuminterpolation assimilation schemes. Ocean Model 69:22-38. doi:10.1016/j.ocemod.2013.05.002 